\title{
The Challenge for the National Traditional Sports in China Under the Background of Globalization
}

\author{
Xiao-Feng HU \\ Sichuan Chengdu Sports College Graduate Department (610041), China \\ 153267717@qq.com
}

Keywords: Globalization, Traditional sports, Challenge.

\begin{abstract}
Globalization is the most significant in today's society. Chinese traditional sports, as the Chinese excellent culture heritage treasures, inherits and develops Chinese sports culture. However, the survival and development of traditional sports in China are facing many new problems with the increasing globalization trend and extremely fast development of economy and sharply social changes. This article discusses Chinese traditional sports the status, opportunities, challenges and proposes corresponding measures.
\end{abstract}

\section{Research purpose}

Today's globalization not only embody in the field of economy, but also in the political, cultural, ideological, and other areas of the extensive social life [1].As in the field of economic globalization brings pros and cons to developing countries, globalization will be an opportunity and a challenge as well to the development of national culture. Chinese traditional sports, as the Chinese excellent culture heritage treasures, inherits and develops Chinese sports culture. However, the survival and development of traditional sports in China are facing many new problems with the increasing globalization trend and extremely fast development of economy and sharply social changes. This article holds a discussion about Chinese traditional sport's the status, opportunities, challenges and proposes corresponding measures.

\section{The research methods}

This paper uses the method of literature material law. We input "the dilemma of traditional sports, globalization," such keywords in China journal full-text database, WeiPuZhongWen science and technology periodical database and Chinese dissertations full-text database, collect a large number of relevant literature, summarized the data analysis, so as to draw relevant conclusions and recommendations.

\section{The results of the study}

\section{Economic globalization promotes national sports globalization}

Like economic and cultural globalization, Sports globalization is the inevitable choice of modern social development [2].Chinese sports faces with the choice of nationalization and modernization once again under the international trend of globalization. It is the wish of the Chinese national sports that merge into sports globalization. However, gradual globalization of Chinese national sports culture is not equal to the assimilation, but to insist on self-position, identity, let alone losing the national spirit in the aura of "integration". Globalization is not a kind of sports big assimilation, but the ethnic sports interactive process that flow of the various national worldwide sports have impact on different regions, different ethnic groups.

\section{The present situation of the national traditional sports in China}

According to the history museum of Chinese sports and the national physical culture and sports 
commission organization experts conducted a national survey data, circulating in our country, has a long history of traditional ethnic sports as many as 977 kinds of (a) [3]. National fitness space provides the national tradition sports development, change the way of production makes some traditional national sports gradually disappear, large development of communication technology made its national traditional sports in our country gradually, the most representative of martial arts and tai chi are subject to the westerners. The development of globalization also makes different culture appear at the same time, resulting in cultural conflict.

The Chinese nation in the long history of its development process, not only for its brilliant Chinese civilization promoted the progress of human society, and to people of all ethnic groups of the industrious, brave and wisdom to create the diversity of national traditional sports. But because of its geographical distribution, there are differences in the degree of development. In the journal published in recent years, however, the present situation of sports development in China has always been the hot spot of the study, the general conclusions include: one, the imbalance of development, national sports development, subject to the limit of the economy such as the local history and culture, development is uneven; Second, the theoretical system of traditional sports is not very perfect, not a scientific system to support the development of the national traditional sports; Three, the lack of competitiveness and the dominant western competitive sports, school education also is given priority to with western education, reduce the competitiveness; Four, less government spending on traditional sports, to a certain extent also hindered the development of[4].The research for the status quo, is conducive to explore the development situation of traditional sports and the corresponding development countermeasures.

\section{The Challenge for the National Traditional Sports in China}

In the age of the western culture, the development of traditional sports in China by the strong impact of western sports culture, national traditional sports has not as before is keen on. The generation of this kind of phenomenon is China's traditional sports project itself lack of interest or people's ideas changed; here I go from the following analysis.

(1)The most prominent feature of traditional ethnic sports is its nationality and region, so traditional sports always shows distinct differences and the cultural diversity. With this nature to eliminate differences, advocating homogeneous trend of globalization, facing strong pressure.

(2) Most of traditional sports exist in developing countries, or vulnerable social groups in developed countries, such as ethnic minorities. It makes the lack of maintain the necessary resources for survival and the development.

(3) There are a various traditional ethnic sports in our country, many are similar. Because of the history, society, culture, folk custom and so on a variety of reasons, is China's traditional sports development showed great imbalance. Our country is in the key period to realize socialist modernization strategic objectives, for a long time, the school sports teaching is limited to a few projects and sports competition, for the development of traditional sports project is rarely[5].

(4) Most traditional sports and traditional way of production and living, such as agricultural production mode, integrated into an organic whole, replaced with the agricultural society to industrial society, is also the basis of traditional ethnic sports are based.

(5) With the development of the society and the acceleration of globalization, traditional culture and modern concept formed sharp conflicts. Modern society full of commercial value, utilitarian, materialism and consumerism and hedonism, originally on the land for a livelihood of people seem to pay more attention to in the present materialistic; Makes the traditional, simple feature of the traditional sports and utilitarianism, cathartic demand in today's society is not consistent.

Information technology develops very fast under the background of economic globalization, and it speeds up the economic and cultural development of ethnic areas, and the traditional way of life has been difficult to adapt to the rapid development of economy, as a result, the survival and development of national traditional sports culture environment changed, led to the loss of some of the national traditional sports culture. At the same time, influenced by western sports, the Olympic 
movement has got widespread attention. The Olympic movement has a relatively complete ideological system, operation way, gradually accepted by various countries, has a relatively broad mass base, these causes western sports occupy absolute advantage [6].

National traditional sports in the modern society still has its peculiar social demand, its unique traditional value lies in its unique properties. For decades the basic direction of the modification of traditional sports is aligning with modern sports. Modern sports emphasize standardization, neat one, ignoring the differences. In this way it conflicts multicultural ecological of traditional sports in nature. Compared with the world's universal modern sports, national sports belong to the niche, it needs new ideas for development. To meet national traditional sports modernization direction. Modern sports are too strong, so that people thinking about national sports, cannot be separated from its bondage.

\section{Conclusion and Suggestion}

With the advent of globalization, the traditional culture exists in our country gradually eliminate, And we must have a sober understanding to this. In the context of the globalization of western centralism, the traditional Chinese culture cannot send out its own voice, completely in a state of "aphasia"[7].Globalization is an irreversible trend, because the wheel of history cannot be back. In the era of globalization, the development of national sports culture, and the progress of social civilization, must correctly handle the traditional and modern, inheritance and innovation, absorption and integration, and many other relations.

National traditional sports are important sources of modern sport, therefore, we must fully realize the national traditional sports major historical significance and practical effect, improve the understanding of the more traditional sports important righteousness, national traditional sports to its rightful place, and at the same time with modern scientific theories and methods of national traditional sports, national traditional sports culture theory research work, give full play to the role of modern media, let the nation and the world people of all ethnic groups to know, understand, accept and participate in the national traditional sports; Make full use of the national culture tradition of cohesion, The use of national sports itself has the function of fitness, entertainment, education, sports, absorb the masses to actively participate in[8].Under the globalization environment, promote national sports status, promote the national sports development. Through the efforts of all aspects, we should maintain and develop its national character at the same time, expand the universal value of the national sports. Let the national traditional sports culture to choose a new implementation, in order to better integrate with modern sports.

\section{References}

[1] ShenLiang.Relationship between eastern and western sports culture review and forward.sports culture Tribune,2008,11.

[2] Deng xinghua Huang Yanjun.Sports globalization tendency of westernization.Journal of guangzhou sports institute,2003(4).

[3] Wu Zeping.The crisis of national traditional sports and countermeasures.Journal of sport culture Tribune,2007(3):27.

[4] XiangKui.The process of modernization in our country nationality tradition sports in the school sports development trend and countermeasures.Hunan normal university,2012.

[5] XieKe,Luo Yanjuan.China's traditional once anti-war present situation and countermeasure analysis.Journal of mass sports, 2011(2).

[6] $\mathrm{Wu}$ Zeping.The development of Chinese national traditional sports are faced with the opportunities and challenges.Chinese wushu research,2011(6):18. 
[7] Wang Gang.People's Olympics and cultural pride.Journal of sport culture Tribune,2005(12):19.

[8] Shi Manman,bao-ping Chen, Yang Juan etc.Yunnan minority drung traditions and unique sports culture research.Journal of sport adds,2014(12). 